\title{
Socio-demographic and disease related characteristics associated with unplanned emergency department visits by cancer patients: a retrospective cohort study
}

\author{
Polly H. Dufton ${ }^{1,2^{*}}$ (D) Allison Drosdowsky ${ }^{3}$, Marie F. Gerdtz ${ }^{1}$ and Mei Krishnasamy ${ }^{1,2,4}$
}

\begin{abstract}
Background: Emergency department (ED) presentations made by patients having cancer treatment are associated with worse outcomes. This study aimed to explore the socio-demographic and disease related characteristics associated with ED presentation, frequent ED presentations, and place of discharge for cancer patients receiving systemic cancer therapies in the ambulatory setting.

Methods: This was a single site, retrospective observational cohort design. Hospital data for patients treated in the Day Oncology Unit of a large public tertiary hospital in Melbourne, Australia between December 2014 and November 2017 were extracted from clinical databases and retrospectively matched to ED attendance records. Andersen's Behavioral Model of Health Service Utilisation provided the conceptual framework for exploring associations between socio-demographic and disease characteristics and ED use.

Results: A total of 2638 individuals were treated in the Day Oncology Unit over the study dates. Of these, 1182 (45\%) made an unplanned ED presentation within 28 days of receiving systemic cancer therapy. One hundred and twentytwo (12\%) patients attended the ED on two or more occasions within 28 days; while 112 (10\%) patients attended the ED four or more times (within 28 days of receiving systemic cancer therapy) within any given 12 month period. Being born outside of Australia was independently related to making an unplanned ED presentation within 28 days of receiving anti-cancer therapy $(p<.01)$ as was being diagnosed with head and neck $(p=.03)$, upper gastrointestinal $(p<.001)$, colorectal $(p<.001)$, lung $(p<.001)$, skin $(p<.001)$ or breast cancer $(p=.01)$.

Conclusions: This study identified a subgroup of cancer patients for whom an ED presentation is more likely. Better understanding of socio-demographic and disease related characteristics associated with the risk of an ED presentation may help inform targeted follow up of patients, to mitigate potentially avoidable ED presentation and optimize outcomes of care.
\end{abstract}

Keywords: Cancer, Oncology, Antineoplastics, Chemotherapy, Emergency department, Risk reduction, Andersen's behavioral model of health service utilization

\footnotetext{
* Correspondence: polly.dufton@austin.org.au

${ }^{1}$ Department of Nursing \& Centre for Cancer Research, The University of

Melbourne, Parkville, VIC, Australia

${ }^{2}$ The Olivia Newton John Cancer, Wellness and Research Centre, Heidelberg,

VIC, Australia

Full list of author information is available at the end of the article
}

(c) The Author(s). 2019 Open Access This article is distributed under the terms of the Creative Commons Attribution 4.0 International License (http://creativecommons.org/licenses/by/4.0/), which permits unrestricted use, distribution, and reproduction in any medium, provided you give appropriate credit to the original author(s) and the source, provide a link to the Creative Commons license, and indicate if changes were made. The Creative Commons Public Domain Dedication waiver (http://creativecommons.org/publicdomain/zero/1.0/) applies to the data made available in this article, unless otherwise stated. 


\section{Introduction}

Patients who present to an Emergency Department (ED) during their cancer treatment are known to have poorer outcomes than those who do not, often experiencing lengthy admission post ED presentation, treatment dose reductions and treatment delays [1-3]. The ED often provides cancer patients access to unscheduled medical care or access to specialist oncology advice for symptoms they are experiencing [4]. At a system level, unplanned ED presentations place substantial burden on hospital resources $[5,6]$. The high rates of unplanned ED presentations made by cancer patients are of increasing concern to the international health care community and efforts have been made to develop strategies to reduce ED presentations that may be potentially avoidable [7].

There is a substantial amount of variance reported for factors associated with unplanned ED presentations by cancer patients. This may be as a result of the heterogeneity within studies, which have included patients on a range of treatments, patients receiving care in acute and ambulatory settings, which have assessed different time frames for readmission and have highly variable study settings representing different models of care and available support services $[1,5,8-10]$. What is known however, is that patients receiving systemic cancer treatment (that is chemotherapy, targeted therapy and immunotherapy) in ambulatory settings have high rates of hospital representation [11-13] many of which may be mitigated through targeted screening or assessment $[14,15]$. Recently, a systematic review of cancer patients' use of EDs by Lash et al., identified a number of social determinants likely to be associated with ED presentation for people with cancer. These included ethnicity, fiscal resources, social policies of the local community, marital status, health literacy, education and income [16]. Social determinants of health have been shown not only to increase the likelihood of cancer, but also to dictate a person's ability to access, navigate and benefit from use of the health care system [17].

A number of interventions aimed at addressing potentially avoidable unplanned, cancer-related ED presentations have been published. In particular, there has been a focus on timely identification and response to patientreported problems through patient navigation and care coordination models. In the U.K., U.S. and Canada, specialist oncology nurse-led models of care have been implemented to provide patients with timely access to telephone consultation, advice and support following receipt of systemic cancer therapies $[18,19]$. These services focus on strengthening patient education for selfmanagement, timely assessment and response to cancer symptoms or treatment side-effects, and helping patients navigate the health care system. They have been shown to reduce ED presentations and subsequent inpatient length of stay [20-23]. However, few studies have described methods to pro-actively identify cancer patients who are most at risk of making unscheduled ED presentations after receiving cancer treatment, and who may subsequently be targeted for follow up to reduce their risk of an unplanned ED presentation and consequent poorer health outcomes [20].

\section{Aims}

This study aimed to explore socio-demographic (patient) and disease related characteristics of cancer patients presenting to an ED within 28 days of receiving infusional, systemic anti-cancer therapy in a Day Oncology Unit (DOU), in order to identify those at greater risk of making an unplanned ED presentation, and to make recommendations for risk stratified models of follow up care.

For the purpose of our study, infusional, systemic anticancer therapy (SACT) was defined as: any type of treatment that uses drugs or other substances to travel through the bloodstream to identify and attack cancer cells, either by blocking or damaging certain enzymes, proteins, or other molecules involved in the growth and spread of cancer cells; or modulation of the immune system; or by stopping normal and cancer cells dividing or by directly causing cell death [24].

The objectives of the study were to explore sociodemographic and disease related characteristics associated with:

1) Making one or more ED presentation within 28 days of receiving SACT;

2) Making multiple ED presentations within 28 days of receiving SACT;

3) Making frequent ( $\geq 4$ within any 12 month period) ED presentations within 28 days of receiving SACT;

4) An ED discharge disposition (i.e. admission or discharge) of primary place of residence.

Andersen's Behavioural Model of Health Service Utilisation was used to guide the exploration of factors that may be associated with ED utilisation in this study. The model has been widely used to explain variations in health service utilisation in community, acute and emergency care settings [25].

\section{Methods}

Setting

This study was conducted at a large, public tertiary hospital in Victoria, Australia which includes a dedicated cancer centre, with two oncology/hematology inpatient wards as well as a dedicated palliative care unit. The centre also consists of a radiotherapy unit and a DOU that has 18 treatment chairs and treats approximately 70 patients per month. The cancer centre services a complex 
case mix of patients and includes a large cancer clinical trials unit and provision for allogeneic hematopoietic stem cell transplantation. The hospital has a large Level II ED and trauma centre. The ED contains a Short Stay Unit (SSU) where patients may be admitted for further care following an ED presentation for a period of no longer than 24h [26].

During business hours at the cancer centre patients who experience or have concerns about symptoms or side-effects of treatment are directed to contact a Clinical Nurse Consultant (hematological cancers, or patients receiving oral therapies or concurrent chemotherapy/radiotherapy in solid tumours) or call the DOU to speak to one of the senior oncology nurses. After hours, patients are directed to call the oncology inpatient wards for symptom support or advice. The DOU does not have a dedicated space for ad-hoc patient reviews, and commonly patients are provided with telephone advice, advised to attend their General Practitioner, or present to the ED.

\section{Sample}

Patients were eligible for inclusion if they received SACT in the DOU between 1 December 2014 and 30 November 2017. Patients treated with subcutaneous treatments or who received supportive therapies only (for example, zoledronic acid) were not eligible and therefore not included in the final dataset.

All episodes of care (that is, any attendance for SACT) in the DOU during the study period were linked to any ED presentation at the study site that fell within 28 days from the date of discharge from the DOU. Episodes of care that were not allocated an ICD-10 code were excluded. The final dataset included specific variables available from the Victorian Admitted Episodes Dataset (VAED) and the Victorian Emergency Minimum Dataset (VEMD). The VAED and VEMD are comprehensive datasets that collect details about the causes, effects and nature of illnesses as well as details on health service use for all public hospitals in the State of Victoria [27, 28].

Demographic and clinical variables collected included age, gender, postcode, country of birth, marital status, preferred language, interpreter required, Aboriginal or Torres Strait Islander status, usual accommodation, attendance source, time of triage, ED length of stay, mode of arrival to ED, triage category using the Australasian Triage Scale, ED discharge destination and inpatient length of stay. Cancer type was classified according to the International Classification of Diseases and Related Health Problems, 10th Revision, Australian Modification (ICD-10-AM) [29]. Data were screened for outliers such as those who made a high number of ED presentations, and who had an exceptionally long ED or inpatient length of stay recorded and were verified through a manual chart review.

\section{Data analysis}

Data were analyzed using IBM SPSS version 25.0 (Chicago, USA). The data analysis framework was developed to address the four research questions set for the study. Univariate analysis was performed, and continuous data reported as mean and standard deviation (SD) unless otherwise stated. Categorical data are reported as frequency and percentage. Country of birth, primary language and use of interpreter for in-hospital communication were highly correlated and thus, only country of birth was included in regression modelling.

Marital status was collapsed from six categories to two categories "married, de facto" and "single, divorced, widowed" representing those reporting having a significant other, or not. Cancer diagnoses were classified according to the ICD-10 coding and were collapsed from 14 categories into 10 with thyroid, bone and soft tissue, rare, gynecological, skin - non-melanoma and unknown primary grouped into 'other' cancers. Hematological cancers were used as the reference category, as they effect both males and females equally, encompass a variety of individual diagnoses and associated symptoms, are the largest tumor stream treated at the cancer center, and had the highest number of unplanned ED presentations.

The Socio-Economic Indexes for Areas (SEIFA) is a product developed by the Australian Bureau of Statistics which ranks areas in Australia according to relative socio-economic advantage and disadvantage [30]. SEIFA codes for all included patient records were ranked from lowest to highest and organized into quintiles. The top $20 \%$ represents those with the highest socioeconomic status, those that fall between 40 and $80 \%$ represent the middle bracket, and the bottom $40 \%$ represent those with the lowest socioeconomic status.

Destination from ED was grouped into two categories (discharged to place of primary residence or admitted to the inpatient area). Country of birth was collapsed in to two categories, born in Australia or born outside of Australia.

A binary outcome was defined for all multivariate logistic regression models as ED presentation/s "Yes/No".

Adjusted odds ratios (AORs), 95\% confidence intervals (95\% CI) and $p$ values are provided for variables associated with ED presentation and place of discharge. $p$ values at $<.05$ were considered statistically significant. Effect size was calculated on AORs [31].

\section{Results}

A total of 2638 individuals were treated for cancer in the DOU during the study period, of which 1182 (45\%) made one or more unplanned ED presentation within 28 days of receiving SACT. Overall, there were 2310 unplanned ED presentations made within 28 days of receiving treatment. 
One hundred and forty-four patients (12\%) presented to the ED on two or more occasions within any given 28 day period after receiving SACT. The average number of ED presentations made within any given 28 day period after receiving treatment was 1.1 and ranged from one ( $n=1038,88 \%)$ to five $(\mathrm{n}=1,0.1 \%)$. One hundred and twelve (10\%) patients were classified as frequent attenders because they had presented to the ED four or more times within any given 12 month period during the study. Most ED presentations $(n=1341,58 \%)$ resulted in the patient being admitted to the inpatient area for further care, with a further $12 \%(n=271)$ being admitted to the SSU. The remaining 30\% of ED episodes $(n=698)$ resulted in the patient being discharged to their place of primary residence.

\section{Patient sample characteristics}

Patient demographics are shown in Table 1. Where individual demographics were used in analyses, age was taken at the first DOU episode of care. Where episodes were used for analyses, age was recalculated at each DOU episode of care accordingly.

\section{Characteristics associated with ED presentation}

Findings reported below with regard to characteristics associated with ED presentations are presented in accordance with Andersen's Behavioural Model of Health Service Utilisation.

Being born outside of Australia was the only sociodemographic factor associated with ED presentation (AOR 1.322, 95\% CI 1.109, 1.576). Patients diagnosed with lung cancer had more than three times the odds (AOR 3.727; 95\% CI 2.781, 4.996) of making an unplanned ED presentation than patients diagnosed with hematological cancers (Table 2).

\section{Characteristics associated with frequent ED presentations} Patients diagnosed with genitourinary cancers had twice the odds (AOR 2.035, 95\% CI 1.053, 3.934) of making two or more ED presentations within any given 28 day period after receiving cancer treatment. This was the only factor found to be independently related to making multiple ED presentations within any given 28 day period after receiving SACT (Table 3).

Being born outside of Australia was significantly associated with making frequent (four or more within an 12 month period) ED presentations within 28 days of receiving SACT (AOR 1.820, 95\% CI 1.178, 2.810, $p<.01$ ) (Table 4).

\section{Characteristics associated with place of discharge}

Increasing age was significantly associated with being admitted to the inpatient area (AOR 1.014, 95\% CI 1.004, $1.024, p<.01)$ for further care. Patients diagnosed with breast cancer (AOR 2.176, 95\% CI 1.387, 3.416, $p<.01$ ) had more than twice the odds of being discharged home from the ED than being admitted to an inpatient area (Table 5).

\section{Discussion}

This study has identified a number of factors associated with unplanned ED presentation after receiving SACT in a DOU. Predisposing factors such as country of birth and age, and disease related factors such as diagnosis were found to be independently associated with ED presentation.

Nearly $45 \%$ of all patients in this study who were treated for cancer in the DOU presented to the ED within 28 days. The number of patients who presented to the ED after receiving SACT in this study is higher than that reported in other Australian studies, which have ranged between 30 and 45\% [5, 9, 32], while international studies have reported ED utilization rates as high as $83 \%$ in patients receiving SACT [10]. Other studies exploring ED utilization rates have however used a variety of methods to identify patients who have been treated in the DOU and who have subsequently attended the ED, which may explain the variance reported. The setting of this study was a large tertiary referral centre that treats patients with complex and rare cancers as well as patients recruited to Phase 1-4 cancer clinical trials. As such, the case mix of patients may represent more complex or unwell patients who are consequently more likely to present to the ED. Higher rates of ED utilization reported internationally may be explained by the inclusion of patients who have received SACT up to 12 months prior to their indexed ED presentation.

The vast majority of studies that have explored ED presentation in the cancer patient population have focused on factors that may be associated with inpatient admission following an ED presentation. This study is unique in its approach to identifying patients who may be at risk of making an ED presentation based on sociodemographic and disease related characteristics identifiable at the initial treatment phase.

To the best of our knowledge this is the first time Andersen's Model has been operationalized to explore factors associated with ED presentation in cancer patients receiving SACT in an ambulatory setting. Our work indicates the relevance of Andersen's Model to explore factors influencing presentation to ED within 28 days of receiving ambulatory-based anti-cancer therapy, and suggests further work is warranted, to explore the relevance and applicability of the model.

\section{Predisposing factors}

Predisposing factors found to be associated with unplanned ED presentation in this study included being 
Table 1 Comparison of demographic factors for patients who did and did not make an ED presentation $(N=2638)$

\begin{tabular}{|c|c|c|c|c|c|c|}
\hline \multirow{2}{*}{$\overline{\text { Age (mean SD) }}$} & \multicolumn{2}{|c|}{ ED presentation absent $(n=1456)$} & \multicolumn{2}{|c|}{ ED presentation present $(n=1182)$} & \multicolumn{2}{|c|}{ Total $(N=2638)$} \\
\hline & $60.83(13.72)$ & & $62.46(14.14)$ & & 61.56 & \\
\hline \multicolumn{7}{|l|}{ Gender (n \%) } \\
\hline Male & 797 & 54.74 & 626 & 52.96 & 1423 & 53.94 \\
\hline Female & 659 & 45.26 & 556 & 47.04 & 1215 & 46.06 \\
\hline \multicolumn{7}{|l|}{ ATSI (n \%) } \\
\hline No & 1286 & 88.32 & 1116 & 94.42 & 2402 & 91.05 \\
\hline Yes & 5 & 0.34 & 4 & 0.34 & 9 & 0.34 \\
\hline \multicolumn{7}{|l|}{ Country of Birth (n \%) } \\
\hline Australia & 868 & 59.62 & 631 & 53.38 & 1499 & 56.82 \\
\hline Country other than Australia & 527 & 36.20 & 548 & 46.36 & 1075 & 40.75 \\
\hline \multicolumn{7}{|l|}{ Preferred Language (n \%) } \\
\hline English & 1249 & 85.78 & 989 & 83.67 & 2238 & 84.84 \\
\hline Language other than English & 126 & 8.65 & 174 & 14.72 & 300 & 11.37 \\
\hline \multicolumn{7}{|l|}{ SEIFA (VIC) (n \%) } \\
\hline $0-40 \%$ & 424 & 29.12 & 395 & 33.42 & 819 & 31.05 \\
\hline $40-80 \%$ & 505 & 34.68 & 369 & 31.22 & 874 & 33.13 \\
\hline$>80 \%$ & 525 & 36.06 & 418 & 35.36 & 943 & 35.75 \\
\hline \multicolumn{7}{|l|}{ Marital status (n \%) } \\
\hline Married/de facto & 904 & 62.09 & 782 & 66.16 & 1686 & 63.91 \\
\hline Single/divorced/widowed & 393 & 26.99 & 363 & 30.71 & 756 & 28.66 \\
\hline \multicolumn{7}{|l|}{ Interpreter (n \%) } \\
\hline No & 1287 & 88.39 & 1053 & 89.09 & 2340 & 88.70 \\
\hline Yes & 92 & 6.32 & 112 & 9.48 & 204 & 7.73 \\
\hline Missing & 77 & 5.29 & 17 & 1.44 & 94 & 3.56 \\
\hline \multicolumn{7}{|l|}{ Tumour stream (n \%) } \\
\hline Head and neck & 62 & 4.26 & 49 & 4.15 & 111 & 4.21 \\
\hline UGl & 83 & 5.70 & 134 & 11.34 & 217 & 8.23 \\
\hline CRC & 124 & 8.52 & 147 & 12.44 & 271 & 10.27 \\
\hline Lung & 108 & 7.42 & 209 & 17.68 & 317 & 12.02 \\
\hline Other & 57 & 3.91 & 29 & 2.45 & 86 & 3.26 \\
\hline Skin & 49 & 3.37 & 49 & 4.15 & 98 & 3.71 \\
\hline Breast & 214 & 14.70 & 175 & 14.81 & 389 & 14.75 \\
\hline Genitourinary & 148 & 10.16 & 97 & 8.21 & 245 & 9.29 \\
\hline CNS & 60 & 4.12 & 36 & 3.05 & 96 & 3.64 \\
\hline Haematological & 551 & 37.84 & 257 & 21.74 & 808 & 30.63 \\
\hline
\end{tabular}

ATSI Aboriginal or Torres Strait Islander status, SEIFA Socio-economic indexes for areas, UGI upper gastrointestinal, CRC colorectal cancer, CNS central nervous system

born outside of Australia, with over 50\% ( $n=548 / 1075)$ of patients in this study born outside of Australia presenting to the ED within 28 days of receiving SACT. A similar Australian study by Craike et al., reported 37.7\% of patients treated in the DOU who were born in a nonEnglish speaking country presented to the ED on at least one occasion [33]. In the present study, of the 1075 (40.8\%) patients born outside of Australia, 300 (27.9\%) recorded a primary language other than English, and of those 199 (66.3\%) needed an interpreter for in-hospital communication. In a recent U.S. study by Ngai et al., a significant relationship was demonstrated between the general population of ED attenders with limited English proficiency, and making unplanned ED re-presentations within $72 \mathrm{~h}$ [34]. Our study found no association between English proficiency and frequent ED presentations, in both 
Table 2 Socio-demographic and disease related factors associated with ED presentation within any 28-day given period after SACT

\begin{tabular}{|c|c|c|c|c|c|c|c|c|c|}
\hline & \multirow[t]{2}{*}{ B } & \multirow[t]{2}{*}{ S.E. } & \multirow[t]{2}{*}{ Wald } & \multirow[t]{2}{*}{$d f$} & \multirow[t]{2}{*}{$p$ value } & \multirow[t]{2}{*}{ OR } & \multicolumn{2}{|c|}{$95 \% \mathrm{Cl}$} & \multirow[t]{2}{*}{ Effect size } \\
\hline & & & & & & & Lower & Upper & \\
\hline Age & .004 & .003 & 1.306 & 1 & .253 & 1.004 & .997 & 1.010 & trivial \\
\hline \multicolumn{10}{|l|}{ Gender } \\
\hline Male & -.078 & .098 & .636 & 1 & .425 & .925 & .763 & 1.121 & trivial \\
\hline \multicolumn{10}{|l|}{ Female (ref) } \\
\hline \multicolumn{10}{|l|}{ Country of birth } \\
\hline Other than Australia & .279 & .090 & 9.716 & 1 & $.002^{*}$ & 1.322 & 1.109 & 1.576 & small \\
\hline \multicolumn{10}{|l|}{ Australia (ref) } \\
\hline \multicolumn{10}{|l|}{ Marital status } \\
\hline Single/divorced/widowed & .092 & .093 & .988 & 1 & .320 & 1.097 & .914 & 1.315 & trivial \\
\hline \multicolumn{10}{|l|}{ Married/de facto (ref) } \\
\hline \multicolumn{10}{|l|}{ SEIFA (VIC) } \\
\hline $0-40 \%$ & .032 & .104 & .097 & 1 & .756 & 1.033 & .843 & 1.266 & trivial \\
\hline $40-80 \%$ & -.082 & .103 & .642 & 1 & .423 & .921 & .753 & 1.127 & trivial \\
\hline$>80 \%$ (ref) & & & 1.268 & 2 & .530 & & & & \\
\hline \multicolumn{10}{|l|}{ Tumour stream } \\
\hline Head and neck & .455 & .212 & 4.622 & 1 & $.032^{*}$ & 1.577 & 1.041 & 2.389 & small \\
\hline UGl & 1.074 & .168 & 41.101 & 1 & $<.001^{* *}$ & 2.927 & 2.108 & 4.064 & medium \\
\hline CRC & .767 & .148 & 26.834 & 1 & $<.001^{* *}$ & 2.154 & 1.611 & 2.879 & small \\
\hline Lung & 1.316 & .149 & 77.458 & 1 & $<.001^{* *}$ & 3.727 & 2.781 & 4.996 & large \\
\hline Other & .136 & .251 & .292 & 1 & .589 & 1.145 & .700 & 1.873 & trivial \\
\hline Skin & .723 & .227 & 10.179 & 1 & $.001^{*}$ & 2.060 & 1.321 & 3.211 & medium \\
\hline Breast & .365 & .144 & 6.443 & 1 & $.011^{*}$ & 1.441 & 1.087 & 1.911 & small \\
\hline Genitourinary & .231 & .159 & 2.104 & 1 & .147 & 1.260 & .922 & 1.721 & small \\
\hline CNS & .253 & .234 & 1.176 & 1 & .278 & 1.288 & .815 & 2.036 & small \\
\hline Haematological (ref) & & & 110.128 & 9 & $<.001^{* *}$ & & & & \\
\hline Constant & -.893 & .224 & 15.828 & 1 & $<.001$ & .409 & & & \\
\hline
\end{tabular}

${ }^{*} p<.05 * * 0<.001$

univariate and multivariate analysis. However, we found that limited English proficiency was associated with making at least one ED presentation after receiving SACT $(p<.001)$, but not with making frequent ED presentations (data not shown). The significant association between being born outside of Australia and making an unplanned ED presentation in this study suggests that increased risk of ED presentation may not be based on language or communication barriers alone, but may be due to additional factors such as being unfamiliar with the Australian health care system. Stage of disease may also be an important factor.

\section{Enabling factors}

A number of international studies have identified several factors that may be associated with ED presentation such as lower socio-economic status [13, 33, 35]. In our study no factors likely to increase likelihood of or mitigate against ED presentation were identified.

\section{Need factors}

Disease related factors found to be associated with an ED presentation (head and neck, UGI, CRC, lung, skin or breast cancer diagnosis) may represent true symptom severity and need for health care but may also indicate levels of unmet supportive care need. In 2013, Aprile et al., reported that $21.6 \%$ of unplanned hospital presentations made by cancer patients were due to the patients' desire for reassurance from their treating specialist [12]. Public use and perception of EDs were explored in an Australian study by Fitzgerald et al., which reported that the main reasons for ED use by the general population were perceived severity of illness, unavailability of alternative health services, and the perception that EDs were able to provide a higher standard of care [36]. More 
Table 3 Socio-demographic and disease related factors associated with two or more ED presentations within any 28-day given period after SACT

\begin{tabular}{|c|c|c|c|c|c|c|c|c|c|}
\hline & \multirow[t]{2}{*}{ B } & \multirow[t]{2}{*}{ S.E. } & \multirow[t]{2}{*}{ Wald } & \multirow[t]{2}{*}{$\mathrm{df}$} & \multirow[t]{2}{*}{$p$ value } & \multirow[t]{2}{*}{ OR } & \multicolumn{2}{|c|}{$95 \% \mathrm{Cl}$} & \multirow[t]{2}{*}{ Effect size } \\
\hline & & & & & & & Lower & Upper & \\
\hline Age & .002 & .007 & .092 & 1 & .762 & 1.002 & .989 & 1.016 & trivial \\
\hline \multicolumn{10}{|l|}{ Gender } \\
\hline Male & -.083 & .209 & .159 & 1 & .690 & .920 & .611 & 1.385 & trivial \\
\hline \multicolumn{10}{|l|}{ Female (ref) } \\
\hline \multicolumn{10}{|l|}{ Country of birth } \\
\hline Other than Australia & .024 & .194 & .015 & 1 & .901 & 1.024 & .701 & 1.497 & trivial \\
\hline \multicolumn{10}{|l|}{ Australia (ref) } \\
\hline \multicolumn{10}{|l|}{ Marital status } \\
\hline Single/divorced/widowed & -.278 & .211 & 1.740 & 1 & .187 & .757 & .500 & 1.145 & small \\
\hline \multicolumn{10}{|l|}{ Married/de facto (ref) } \\
\hline \multicolumn{10}{|l|}{ SEIFA (VIC) } \\
\hline $0-40 \%$ & -.191 & .231 & .687 & 1 & .407 & .826 & .525 & 1.298 & small \\
\hline $40-80 \%$ & .020 & .221 & .008 & 1 & .930 & 1.020 & .661 & 1.574 & trivial \\
\hline$>80 \%$ (ref) & & & .992 & 2 & .609 & & & & \\
\hline \multicolumn{10}{|l|}{ Tumour stream } \\
\hline Head and neck & -.309 & .565 & .299 & 1 & .584 & .734 & .243 & 2.220 & small \\
\hline UGl & .072 & .343 & .045 & 1 & .833 & 1.075 & .549 & 2.104 & trivial \\
\hline CRC & -.127 & .347 & .133 & 1 & .716 & .881 & .446 & 1.740 & small \\
\hline Lung & .163 & .296 & .304 & 1 & .582 & 1.177 & 659 & 2.105 & trivial \\
\hline Other & .284 & .578 & .242 & 1 & .623 & 1.329 & .428 & 4.126 & small \\
\hline Skin & .500 & .442 & 1.284 & 1 & .257 & 1.649 & .694 & 3.919 & small \\
\hline Breast & -.255 & .358 & .505 & 1 & .477 & .775 & .384 & 1.564 & small \\
\hline Genitourinary & .711 & .336 & 4.467 & 1 & $.035^{*}$ & 2.035 & 1.053 & 3.934 & medium \\
\hline CNS & .666 & .472 & 1.993 & 1 & .158 & 1.947 & .772 & 4.910 & medium \\
\hline Haematological (ref) & & & 10.229 & 9 & .332 & & & & \\
\hline Constant & -2.049 & .502 & 16.673 & 1 & $<.001$ & .129 & & & \\
\hline
\end{tabular}

${ }^{*} p<.05 * * 0<.001$

recently, Phillip et al., reported that patients with advanced cancer frequently presented to the ED as a means of accessing specialist oncology care, to receive treatment for worsening symptoms, or symptoms that they had been instructed to attend the ED for, such as a fever [4]. To the best of our knowledge, no studies have explored the decision-making process behind ED presentations for patients receiving active cancer treatment.

Results from this study have shown that patients who were of an older age were significantly more likely to be admitted to either the SSU or to an inpatient unit, than be discharged home following an ED presentation. This may suggest the presence of other comorbidities alongside a diagnosis of cancer, and thus a higher level of care complexity or clinical acuity $[3,37,38]$. This finding is consistent with international literature that has previously identified a significant relationship between older age and inpatient admission following an ED presentation [39, 40].

Patients diagnosed with breast cancer were more likely to be discharged home than be admitted to an inpatient area after an ED presentation. Previous studies have explored risk factors for inpatient admission following an ED presentation, but no studies were identified that explored the factors associated with being discharged home from the ED. Patients with early stage breast cancer are commonly treated with adjuvant chemotherapy and subsequently experience considerable treatment related toxicities and are known to make higher numbers of unplanned hospital visits [41, 42]. This may explain the higher frequency of ED presentations seen in this study, but also why ED presentation by such patients is unlikely to result in admission. 
Table 4 Socio-demographic and disease related factors associated with making frequent ( $\geq 4$ within any 12 month period) ED presentations within 28 days of receiving SACT

\begin{tabular}{|c|c|c|c|c|c|c|c|c|c|}
\hline & \multirow[t]{2}{*}{ B } & \multirow[t]{2}{*}{ S.E. } & \multirow[t]{2}{*}{ Wald } & \multirow[t]{2}{*}{$d f$} & \multirow[t]{2}{*}{$p$ value } & \multirow[t]{2}{*}{ OR } & \multicolumn{2}{|l|}{$95 \% \mathrm{Cl}$} & \multirow[t]{2}{*}{ Effect size } \\
\hline & & & & & & & Lower & Upper & \\
\hline Age & .005 & .008 & .403 & 1 & .525 & 1.005 & .989 & 1.021 & trivial \\
\hline \multicolumn{10}{|l|}{ Gender } \\
\hline Male & -.096 & .230 & .176 & 1 & .675 & .908 & .579 & 1.425 & trivial \\
\hline \multicolumn{10}{|l|}{ Female (ref) } \\
\hline \multicolumn{10}{|l|}{ Country of birth } \\
\hline Other than Australia & .599 & .222 & 7.293 & 1 & $<.01^{*}$ & 1.820 & 1.173 & 1.942 & small \\
\hline \multicolumn{10}{|l|}{ Australia (ref) } \\
\hline \multicolumn{10}{|l|}{ Marital status } \\
\hline Single/divorced/widowed & .074 & .227 & .105 & 1 & .764 & 1.076 & .690 & 1.680 & trivial \\
\hline \multicolumn{10}{|l|}{ Married/de facto (ref) } \\
\hline \multicolumn{10}{|l|}{ SEIFA (VIC) } \\
\hline $0-40 \%$ & -.111 & .259 & .184 & 1 & .668 & .895 & .539 & 1.486 & trivial \\
\hline $40-80 \%$ & .085 & .257 & .109 & 1 & .741 & 1.088 & .658 & 1.800 & trivial \\
\hline$>80 \%$ (ref) & & & .605 & 2 & & & & & \\
\hline \multicolumn{10}{|l|}{ Tumour stream } \\
\hline Head and neck & -1.585 & 1.038 & 2.329 & 1 & .127 & .205 & .027 & 1.569 & large \\
\hline UGl & .462 & .340 & 1.852 & 1 & .174 & 1.587 & .816 & 3.088 & small \\
\hline CRC & .498 & .326 & 2.335 & 1 & .127 & 1.645 & .869 & 3.115 & small \\
\hline Lung & .038 & .326 & .014 & 1 & .907 & 1.039 & .549 & 1.968 & trivial \\
\hline Other & .170 & .654 & .068 & 1 & .795 & 1.185 & .329 & 4.269 & trivial \\
\hline Skin & -1.451 & 1.038 & 1.955 & 1 & .162 & .234 & .031 & 1.792 & large \\
\hline Breast & -.548 & .432 & 1.612 & 1 & .204 & .578 & .248 & 1.347 & small \\
\hline Genitourinary & .176 & .399 & .195 & 1 & .659 & 1.193 & .545 & 2.609 & trivial \\
\hline CNS & -1.196 & 1.043 & 1.314 & 1 & .252 & .302 & .039 & 2.337 & large \\
\hline Haematological (ref) & & & 14.981 & 9 & .091 & & & & \\
\hline Constant & -2.886 & .592 & 23.766 & 1 & .000 & .065 & & & \\
\hline
\end{tabular}

${ }^{*} p<.05 * * p<.001$

Patients with haematological cancers are known to have high rates of ED utilization due to the acuity and complexity of these diseases and their treatments [8, 37]. In this study, patients diagnosed with hematological cancers made the largest number of ED presentations, but which are comparatively low to the number of patients treated for hematological cancers in the DOU. At the study site patients with haematological cancers have timely access to specialist haematology nurse coordinators who provide telephone support during business hours. This may explain the low numbers of ED presentations by haematology patients in our study. Equivalent nurse coordinators are only available for patients diagnosed with solid tumours who are receiving oral anti-cancer therapies or concurrent chemotherapy and radiotherapy. Outside of these treatment modalities, patients only recourse is to contact the DOU and speak a senior oncology nurse where they are provided with telephone advice or advised to present to the ED for further assessment.

\section{Conclusion}

Findings from this retrospective analysis suggest that it may be possible to proactively identify patients at greatest risk of making an unplanned ED presentation after receiving SACT in a DOU setting.

Further research is needed to test the clinical utility of socio-demographic and disease related factors, health behaviors and outcomes of health service use that are not currently routinely collected as a component of administrative health datasets, but which may be predictive of an unplanned ED presentation after receiving SACT. 
Table 5 Socio-demographic and disease related factors associated with discharge from ED to primary place of residence

\begin{tabular}{|c|c|c|c|c|c|c|c|c|c|}
\hline & \multirow[t]{2}{*}{ B } & \multirow[t]{2}{*}{ S.E. } & \multirow[t]{2}{*}{ Wald } & \multirow[t]{2}{*}{$d f$} & \multirow[t]{2}{*}{$p$ value } & \multirow[t]{2}{*}{ OR } & \multicolumn{2}{|l|}{$95 \% \mathrm{Cl}$} & \multirow[t]{2}{*}{ Effect size } \\
\hline & & & & & & & Lower & Upper & \\
\hline Age & .014 & .005 & 7.754 & 1 & $.005^{*}$ & 1.014 & 1.004 & 1.024 & trivial \\
\hline \multicolumn{10}{|l|}{ Gender } \\
\hline Male & -101 & .160 & .401 & 1 & .527 & 1.107 & .809 & 1.236 & small \\
\hline \multicolumn{10}{|l|}{ Female (ref) } \\
\hline \multicolumn{10}{|l|}{ Country of birth } \\
\hline Other than Australia & .096 & .145 & .435 & 1 & .510 & 1.100 & .828 & 1.207 & small \\
\hline \multicolumn{10}{|l|}{ Australia (ref) } \\
\hline \multicolumn{10}{|l|}{ Marital status } \\
\hline Single/divorced/widowed & -.058 & .150 & .151 & 1 & .698 & .944 & .704 & 1.421 & small \\
\hline \multicolumn{10}{|l|}{ Married/de facto (ref) } \\
\hline \multicolumn{10}{|l|}{ SEIFA (VIC) } \\
\hline $0-40 \%$ & .303 & .167 & 3.304 & 1 & .069 & 1.354 & .977 & 1.877 & small \\
\hline $40-80 \%$ & .254 & .167 & 2.307 & 1 & .129 & 1.209 & .929 & 1.790 & trivial \\
\hline$>80 \%$ (ref) & & & 3.911 & 2 & .141 & & & & \\
\hline \multicolumn{10}{|l|}{ Tumour stream } \\
\hline Head and neck & -.222 & .347 & .409 & 1 & .522 & .801 & .406 & 1.582 & small \\
\hline UGl & .373 & .274 & 1.853 & 1 & .173 & 1.453 & .402 & 2.487 & small \\
\hline CRC & -.399 & .230 & 3.014 & 1 & .083 & .671 & .428 & 1.053 & small \\
\hline Lung & .161 & .228 & .501 & 1 & .479 & 1.175 & .752 & 1.836 & small \\
\hline Other & .653 & .565 & 1.338 & 1 & .247 & 1.922 & .635 & 5.815 & medium \\
\hline Skin & .377 & .400 & .887 & 1 & .346 & 1.457 & .666 & 3.191 & small \\
\hline Breast & -.778 & .230 & 11.431 & 1 & $.001^{*}$ & .459 & .293 & .721 & medium \\
\hline Genitourinary & .155 & .298 & .269 & 1 & .604 & 1.167 & .651 & 2.092 & trivial \\
\hline CNS & -.243 & .398 & .372 & 1 & .542 & .784 & .359 & 1.712 & small \\
\hline Haematological (ref) & & & 27.564 & 9 & $.001^{*}$ & & & & \\
\hline Constant & .108 & .360 & .090 & 1 & .765 & 1.114 & & & \\
\hline
\end{tabular}

${ }^{*} p<.05{ }^{* *} p<.001$

In this study, disease related factors such as being diagnosed with head and neck, upper gastrointestinal, colorectal, lung, melanoma and breast cancers were significantly related to risk of ED presentation after receiving SACT in the DOU setting, and were a stronger predictor of ED presentation than socio-demographic characteristics. These findings could be used to proactively identify patients for targeted follow up.

Drawing on these data and best available evidence, findings from this study are being used to develop, implement and evaluate a nurse-led Symptom and Urgent Review Clinic service that will provide proactive follow-up and support to patients identified as high risk of making unplanned ED presentations. The clinic will include standardized telephone triage and physical assessment for cancer patients experiencing disease or treatment-related symptoms.

\section{Limitations}

The limitations of the administrative databases make drawing conclusions about why certain cohorts are more likely to make unplanned ED presentations challenging. Important variables that may be associated with $\mathrm{ED}$ presentation such as stage of disease and those receiving multi-modality treatment are not currently captured in these datasets in Victoria, Australia.

This study was conducted at a single site and therefore may not generalizable to other healthcare settings. The models of care to support patients outside the hospital setting who experience cancer and treatment related toxicities, the case mix of patients treated at individual settings and the difference in health systems internationally means that risk factors for ED presentation may differ according to local structures. 


\section{Abbreviations}

DOU: Day Oncology Unit; ED: Emergency Department; SACT: Systemic anticancer therapy

\section{Acknowledgements}

None.

\section{Authors' contributions}

All authors conceptualized and designed the study. PD carried out data collection and analysis and drafted the paper. AD contributed to data analysis and interpretation. MFG and MK assisted with data interpretation. All authors have approved the submitted version.

\section{Funding}

Funding was generously provided by the Nurses Memorial Centre and the Nurses Board of Victoria Legacy Limited. The funding institutions have not taken part in the scientific work regarding design of the study, collection, analysis, and interpretation of data, and writing of manuscript.

\section{Availability of data and materials}

The datasets used and/or analysed during the current study are available from the corresponding author on reasonable request.

\section{Ethics approval and consent to participate}

Ethics approval was granted by Austin Health Human Research Ethics Committee (LNR/15/AUSTIN/512). Administrative approval was granted for access to and use of electronic medical records for this study. Consent was not obtained from individuals as all data were collected as part of routine healthcare and accessed retrospectively. Data was de-identified at the time of collection.

\section{Consent for publication}

Not applicable

\section{Competing interests}

The authors declare that they have no competing interests.

\section{Author details}

'Department of Nursing \& Centre for Cancer Research, The University of Melbourne, Parkville, VIC, Australia. ${ }^{2}$ The Olivia Newton John Cancer, Wellness and Research Centre, Heidelberg, VIC, Australia. ${ }^{3}$ Department of Cancer Experiences Research, Sir Peter McCallum Cancer Centre, Parkville, VIC, Australia. ${ }^{4}$ Victorian Comprehensive Cancer Centre, Parkville, VIC, Australia.

Received: 26 January 2019 Accepted: 3 September 2019 Published online: 06 September 2019

\section{References}

1. Oatley M, Fry M, Mullen L. A cross-sectional study of the clinical charcateristics of cancer patients presenting to one tertiary referral emergency department. International Emergency Nursing. 2016;24:35-8.

2. Kotajima F, Kobayashi K, Sakaguchi H, Nemoto M. Lung cancer patients frequently visit the emergency room for cancer-related and -unrelated issues. Mol Clin Oncol. 2014;2:322-6.

3. Barbera B, Atzema C, Sutradhar R, Seow H, Howell D, Husain A, et al. Do patient-reported symptoms predict emergency department visits in cance patients? A population based analysis. Ann Emerg Med. 2012;61 (4):427-37.

4. Phillip J, Remedios C, Breen S, Weiland T, Willenberg L, Boughey M, et al. The experiences of patients with advanced cancer and caregivers presenting to emergency departments: a qualitative study. Palliat Med. 2018:32(2):439-46.

5. McKenzie H, Hayes L, White K, Cox K, Fethney J, Boughton M, et al. Chemotherapy outpatients' unplanned presentations to hospital: a retrospective study. Support Care Cancer. 2011:19:963-9.

6. Antonuzzo A, Vasile E, Sbrana A, Lucchesi M, Galli L, Brunetti IM, et al. Impact of a supportive care service for cancer outpatients: managament and reduction of hospitalizations. Preliminary results of an integrated model of care. Support Care Cancer. 2017:25:209-12.

7. Young A, Marshall E, Krzyzanowska M, Robinson B, Brown S, Collinson F, et al. Responding to acute care needs of patients with cancer: recent trends across continents. Oncologist. 2016;21:301-7.
8. van der Meer DM, Weiland T, Phillip J, Jelinek GA, Boughey M, Knott J, et al. Presentation patterns and outcomes of patients with cancer accessing care in emergency departments in Victoria, Australia. Supportive Care in Cancer. 2016:24:1251-60.

9. Livingston PM, Craike M, Considine J. Unplanned presentations to emergency departments due to chemotherapy induced complications: Opportunities for improving service delivery. Australas Emerg Nurs J. 2011; 14:62-8.

10. Prince RM, Powis M, Zer A, Atenafu EG, Krzyzanowska MK. Hospitalisations and emergency department visits in cancer patients receiving systemic therapy: Systematic review and meta-analysis. Eur J Cancer Care (Engl). 2019;28:e12909

11. O'Neill CB, Atoria CL, O'Reilly EM, Henman MC, Bach PB, Elkon EB. Hospitalizations in older adults with advanced cancer. The role of chemotherapy. J Oncol Pract. 2016;12(2):e135-e48.

12. Aprile G, Pisa FE, Follador A, Foltran L, De Pauli F, Mazzer M, et al. Unplanned presentations of cancer outpatients: a retrospective cohort study. Support Care Cancer. 2013;21:397-404.

13. Wong TH, Lau ZY, Ong WS, Tan KB, Wong YJ, Farid M, et al. Cancer patients as frequent attenders in emergency departments: a national cohort study. Cancer Medicine. 2018;7:4434-13.

14. Delgado-Guay MO, Kim YJ, Shin SH, Chisholm G, Williams J, Allo J, et al. Avoidable and unavoidable visits to the emergency department among patients with advanced cancer receiving outpatient palliative care. J Pain Symptom Manag. 2015;49(3):497-504

15. Duflos C, Antoun S, Loirat P, DiPalma M, Minvielle E. Identification of appropriate and potentially avoidable emergency department referrals in a tertiary cancer care centre. Support Care Cancer. 2017;25(8):2377-85.

16. Lash RS, Bell JB, Reed SC, Poghosyan H, Rodgers J, Kim KK, et al. A systematic review of emergency department use amoung cancer patients. Cancer Nurs. 2017;20(2):135-44

17. Maniar N, Wiedt T, Wender R. Understanding the social determinants of Cancer: challenges, opportunities, and pathways to success. In: Hopewood P, Milroy MK, editors. Quality Cancer Care. Cham, Switzerland: Springer International Publishing; 2018. p. 37-60.

18. Stacey D, Green E, Ballantyne B, Tarasuk J, Skrutkowski M, Carley M, et al. Implementation of symtpom protocols for nurses providing telephonebased cancer symptom managament: a compartive case study. Worldviews Evid-Based Nurs. 2016;13(6):420-31.

19. Reid J. Utility, caller, and patient profile of a novel chemotherapy telephone helpline service within a regional cancer centre in Northern Ireland. Cancer Nurs. 2011:34(3):e27-32.

20. Handley NR, Schuchter LM, Bekelman JE. Best practices for reducing unplanned acute care for patients with cancer. J Oncol Pract. 2018;14(5): 306-13.

21. Pirschel C. How Oncology Nurses Provide Quality Care Through Telephone Triage. ONS Voice. 2018.

22. Hoverman JR, Klein I, Harrison DW, Hayes JE, Garey JS, Harrell R, et al. Opening the black box: the impact of an oncology managament program consisiting of level I pathways and an outbound nurse call system. J Oncol Pract. 2014;10:63-7.

23. Montero AJ, Stevenson J, Guthrie AE, Best C, Goodman LM, Shrotriya S, et al. Reducing unplanned medical oncology readmissions by improving outpatient care transitions: a process improvement project at the Cleveland Clinic. J Oncol Pract. 2016;12(5):e594-601.

24. NCl Dictionary of Cancer Terms [Internet]. National Cancer Institute. 2019 [cited 31 December 2018]. Available from: https:/www.cancer.gov/ publications/dictionaries/cancer-terms/def/systemic-chemotherapy

25. Babitsch B, Gohl D, von Lengerke T. Re-visiting Andersen's Behavioral Model of Health Services Use: a systematic review of studies from 1998-2011. GMS Psycho-Social Medicine 2012;9(Doc11).

26. Guidelines for emergency department short stay units [Internet]. Www2. health.vic.gov.au. 2019 [cited 19 November 2018]. Available from: https:// www2.health.vic.gov.au/about/publications/policiesandquidelines/ guidelines-emergency-department-short-stay-may-2017

27. Victorian Emergency Minimum Dataset (VEMD) [Internet]. Www2.health.vic. gov.au. 2019 [cited 11 August 2018]. Available from: https://www2.health. vic.gov.au/hospitals-and-health-services/data-reporting/health-datastandards-systems/data-collections/vemd

28. Victorian Admitted Episodes Dataset [Internet]. Www2.health.vic.gov.au. 2019 [cited 11 August 2018]. Available from: https:/www2.health.vic.gov.au/ 
hospitals-and-health-services/data-reporting/health-data-standards-systems/ data-collections/vaed

29. ICD-10-AM/ACHI/ACS [Internet]. 2019 [cited 10 November 2018]. Available from: https://www.accd.net.au/icd10.aspx.

30. Australian Bureau of Statistics. Socio-Economic Indexes for Areas 2018 [Available from: http:/www.abs.gov.au/websitedbs/censushome.nsf/home/seifa.

31. Olivier J, May WL, Bell ML. Relative effect sizes for measures of risk. Communications in Statistics. 2017;46(14):6774-81.

32. Tang M, Horsley $\mathrm{P}$, Lewis CR. Emergency department presentations in early stage breast cancer patients receiving adjuvant and neoadjuvant chemotherapy. Intern Med J. 2018:48:583-7.

33. Craike MJ, Livingston TM, Considine J. Emergency department presentations of patients from CALDB receiving chemotherapy in day oncology settings. Australas Emerg J. 2010;13:111-6.

34. Ngai KM, Grudzen CR, Lee R, Tong VY, Richardson LD, Fernandez A. The association between limited English proficiency and unplanned emergency department revisits within 72 hours. Ann Emerg Med. 2016;68(2):213-21.

35. Henson LA, Higginson IJ, Gao W. What factors influence emergency department visits by patients with cancer at the end of life? Analysis of a 124,030 patient cohort. Palliat Med. 2018;32(2):426-38.

36. Fitzgerald G, Toloo G, Aitken P, Keijzers G, Scuffham P. Public use and perceptions of emergency departments: a population survey. Emerg Med Australas. 2015;27:336-42.

37. Whitney RL, Bell JF, Tancredi DJ, Romano PS, Bold RJ, Joseph JG Hospitalization rates and predictors of rehospitalization among individuals with advanced cancer in the year after diagnosis. J Clin Oncol. 2017:35(31): 3610-7.

38. Nguyen B, Tremblay D, Mathieu L, Groleau D. Mixed method exploration of the medical, service-related, and emotional reasons for emergency room visits of older cancer patients. Supportive Care Cancer. 2016;24:2549-56.

39. Rivera DR, Gllicchio L, Brown J, Kyriacou DN, Shelburne N. Trends in adult cancer-related emergency department utilization an analysis of data from the nationwide emeregncy department sample. JAMA Oncology. 2017;10: e172450.

40. Tanaka T, Taguri M, Fumita S, Okamoto K, Matsuo Y, Hayashi H. Retrospective study of unplanned hospital admission for metastatic cancer patients visiting the emergency department. Support Care Cancer. 2017;25: 1409-15.

41. Chan A, Soh D, Ko Y, Huang Y, Chiang J. Charcateristics of unplanned hospital admissions due to drug-related problems in cancer patients. Support Care Cancer. 2014;22:1875-81.

42. Baena-Canada JM, Estalella-Mendoza S, Rosado-Varela P, Exposito-Alvarez I, Gonzalez-Guerrero M, Diaz-Blanco MC, et al. Use of health-care services during chemotherapy for breast cancer. Eur J Cancer. 2012;48:3328-34.

\section{Publisher's Note}

Springer Nature remains neutral with regard to jurisdictional claims in published maps and institutional affiliations.

Ready to submit your research? Choose BMC and benefit from:

- fast, convenient online submission

- thorough peer review by experienced researchers in your field

- rapid publication on acceptance

- support for research data, including large and complex data types

- gold Open Access which fosters wider collaboration and increased citations

- maximum visibility for your research: over $100 \mathrm{M}$ website views per year

At $\mathrm{BMC}$, research is always in progress.

Learn more biomedcentral.com/submissions 